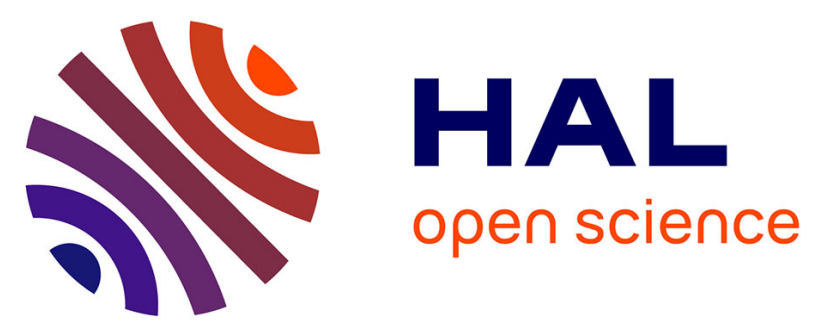

\title{
Influence of inflammasome pathway activation in macrophages on the matrix metalloproteinase expression of human hepatic stellate cells
}

Sacha Robert, Thomas Gicquel, Aude Bodin, Alain Fautrel, Emiliano Barreto, Tatiana Victoni, Vincent Lagente, Elisabeth Boichot

\section{To cite this version:}

Sacha Robert, Thomas Gicquel, Aude Bodin, Alain Fautrel, Emiliano Barreto, et al.. Influence of inflammasome pathway activation in macrophages on the matrix metalloproteinase expression of human hepatic stellate cells. International Immunopharmacology, 2019, 72, pp.12-20. 10.1016/j.intimp.2019.03.060 . hal-02120881

HAL Id: hal-02120881

https://hal-univ-rennes1.archives-ouvertes.fr/hal-02120881

Submitted on 21 Dec 2021

HAL is a multi-disciplinary open access archive for the deposit and dissemination of scientific research documents, whether they are published or not. The documents may come from teaching and research institutions in France or abroad, or from public or private research centers.
L'archive ouverte pluridisciplinaire HAL, est destinée au dépôt et à la diffusion de documents scientifiques de niveau recherche, publiés ou non, émanant des établissements d'enseignement et de recherche français ou étrangers, des laboratoires publics ou privés.

\section{(ㄷ)(1) $\$$}

Distributed under a Creative Commons Attribution - NonCommerciall 4.0 International 


\section{Stress responses in fishes: from molecular to evolutionary processes}

PETITJEAN Quentin ${ }^{1,2}$, JEAN Séverine ${ }^{2}$, GANDAR Allison ${ }^{2}$, CÔTE Jessica ${ }^{1}$, LAFFAILLE Pascal $^{2}$, JACQUIN Lisa ${ }^{1}$

${ }^{1}$ Laboratoire EDB Évolution \& Diversité Biologique UMR 5174 ; Université de Toulouse, Université Toulouse 3 Paul Sabatier, UPS, CNRS, IRD; 118 route de Narbonne, 31062 Toulouse, France.

${ }^{2}$ Laboratoire ECOLAB UMR 5245 ; CNRS, INPT-ENSAT, Université Toulouse 3 Paul Sabatier ; avenue de l'Agrobiopole, 31326 Castanet-Tolosan, France.

\section{Corresponding author:}

Dr Lisa Jacquin

Université de Toulouse

Laboratoire Evolution et Diversité Biologique

118 route de Narbonne, 31062 Toulouse cedex 9

Tel: 033561556474

Email: lisa.jacquin@univ-tlse3.fr

Running title: Evolution of fish stress responses

Word count: 5272 words 

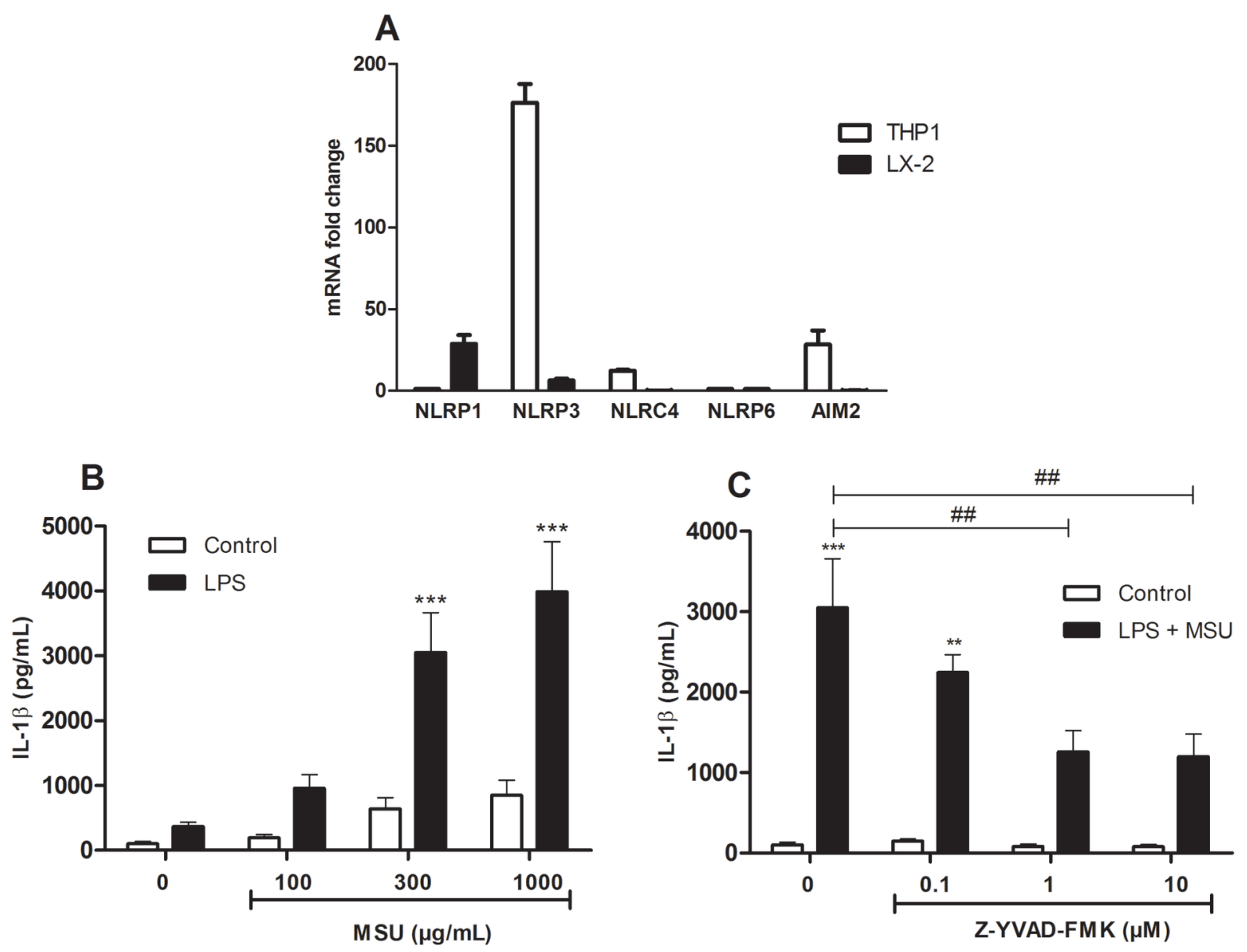

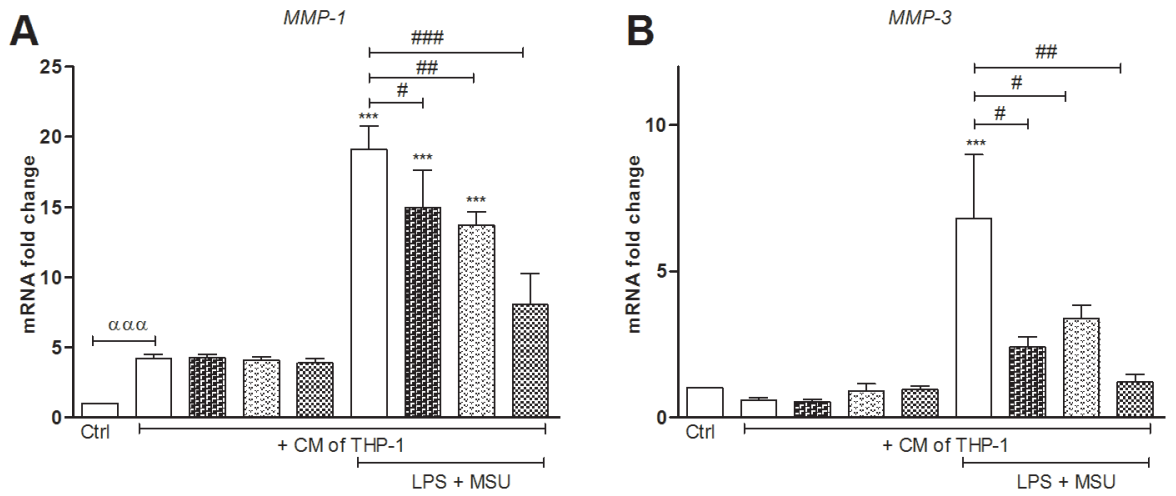

C

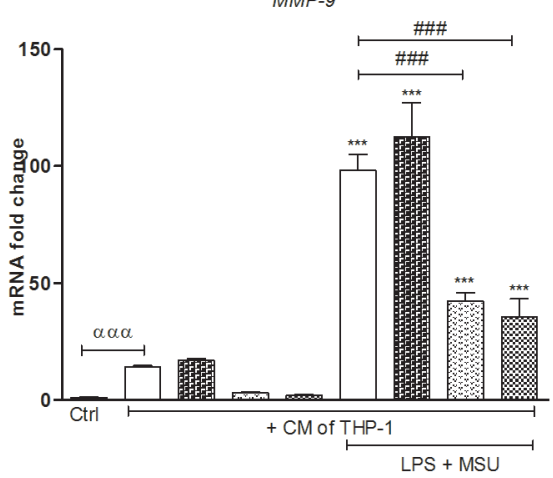

D

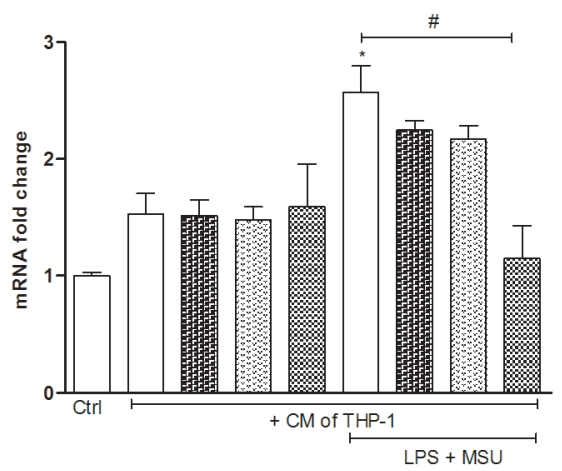



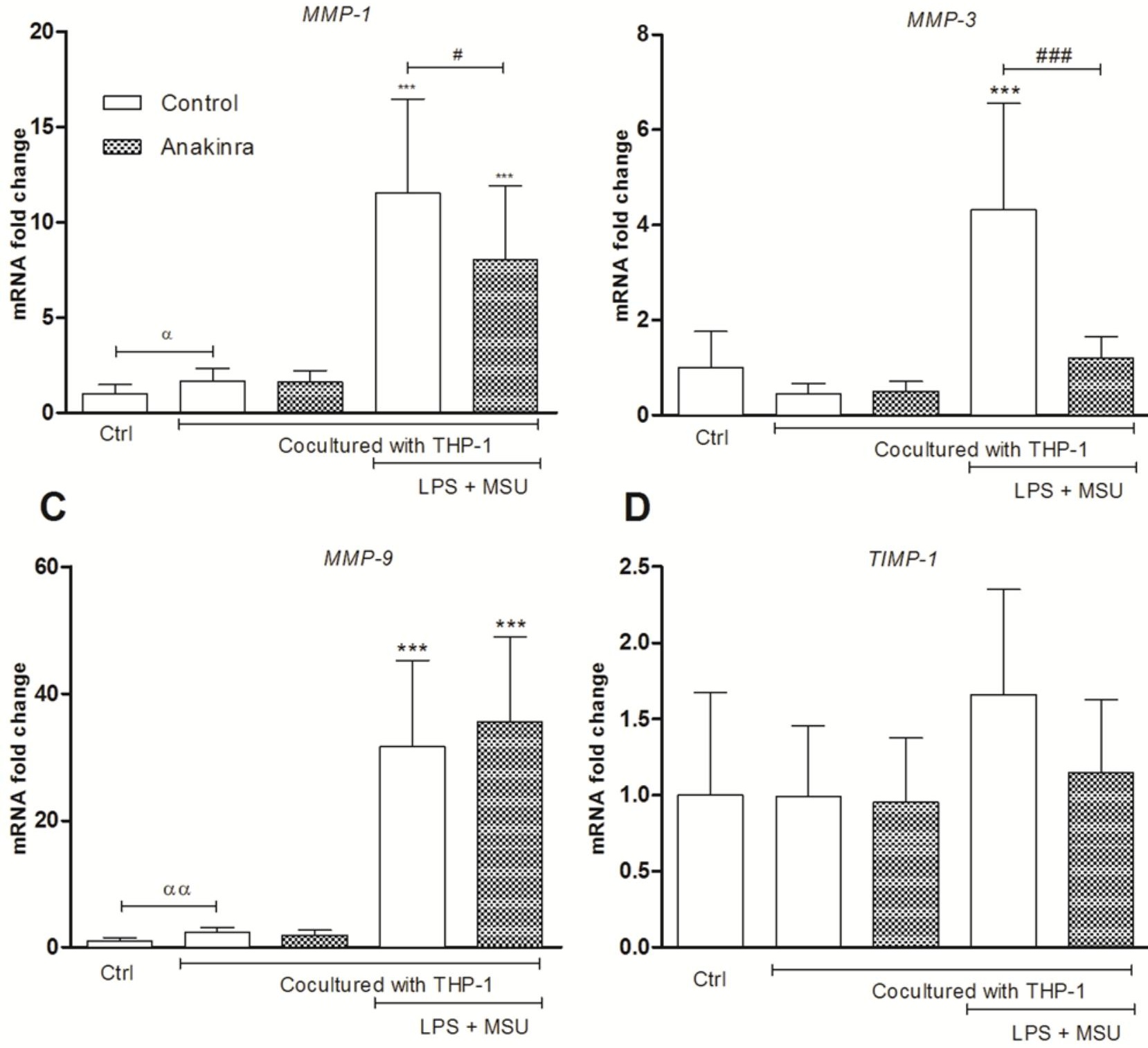
A

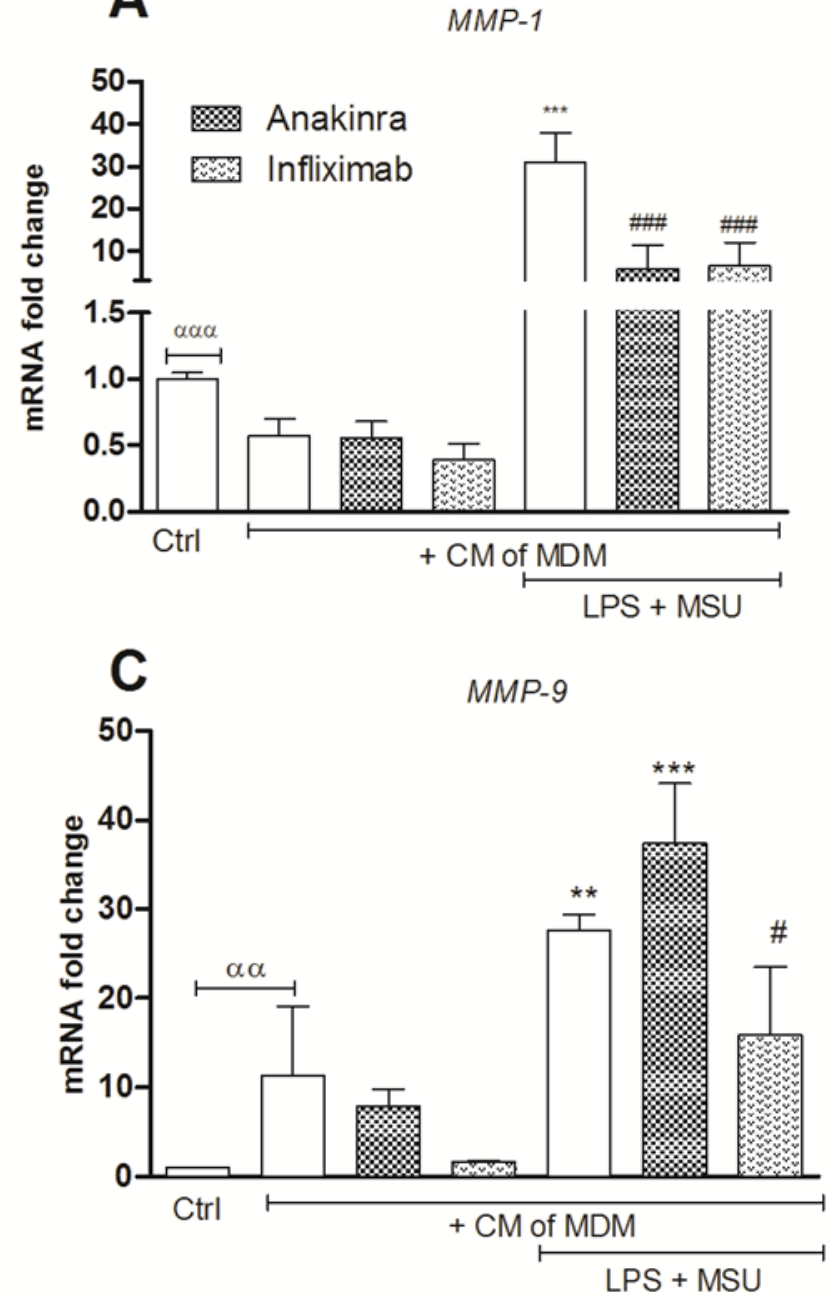

MMP-3
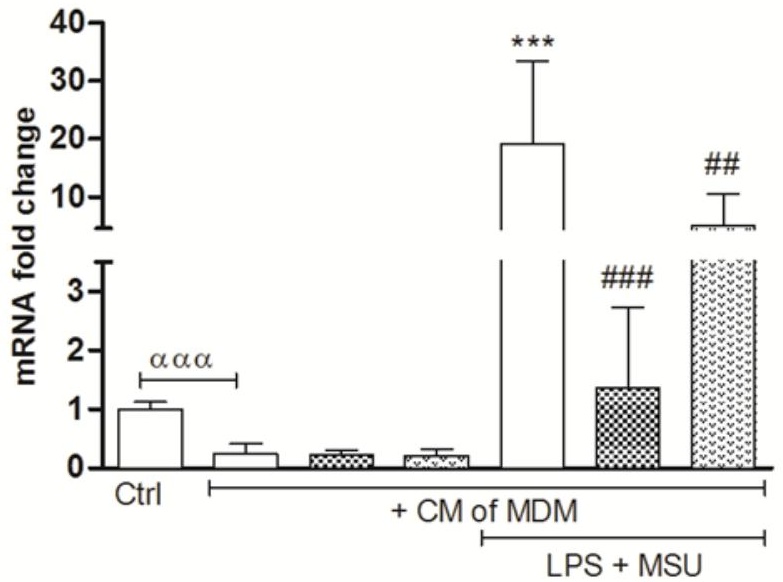

D

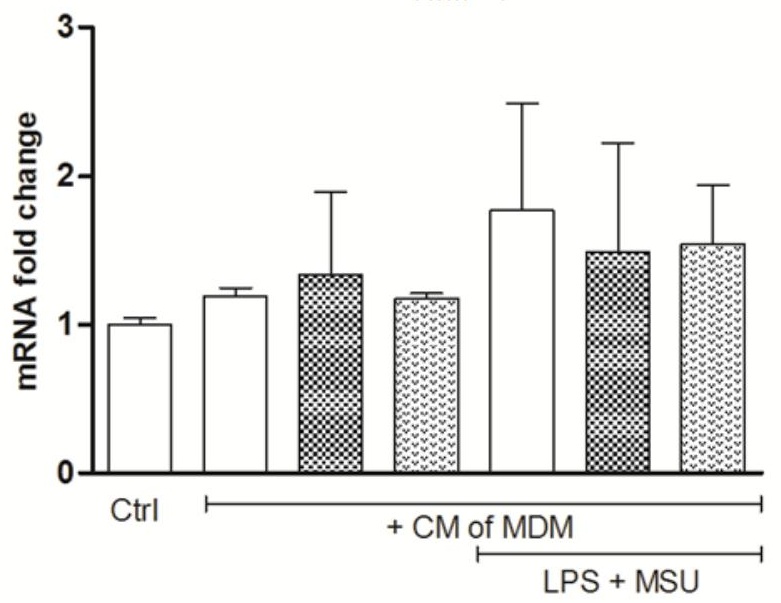


A

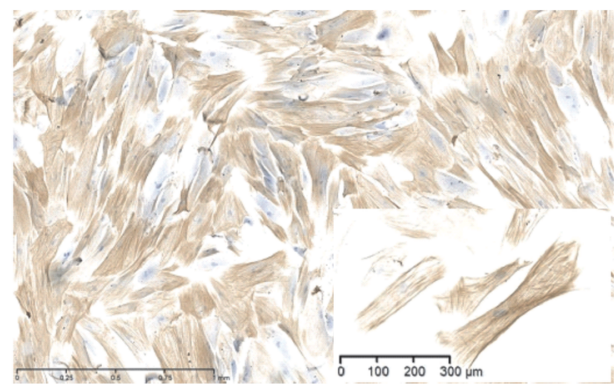

Anakinra $1 \mu \mathrm{gg} / \mathrm{mL}$
B

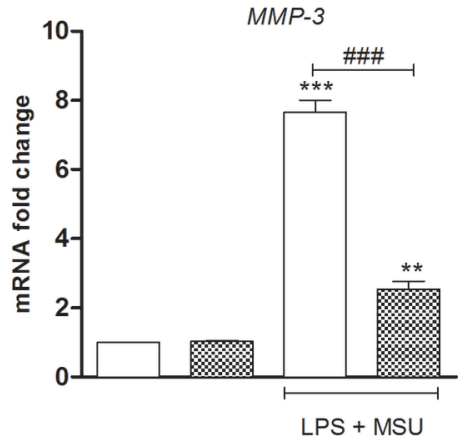

D

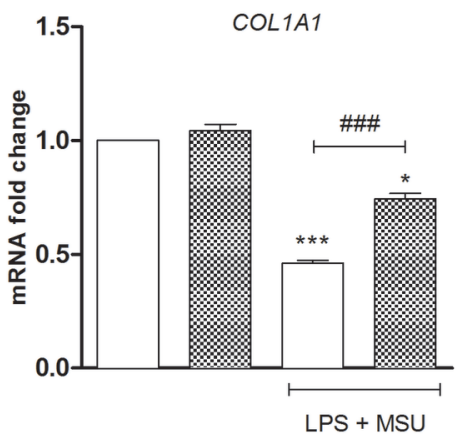

C

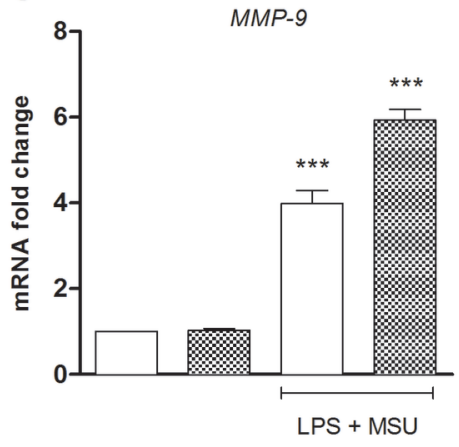

E

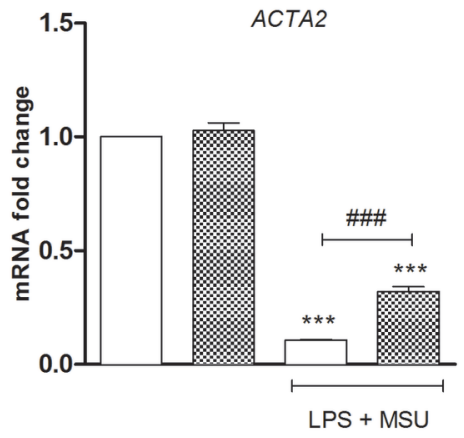


Table 1 - Primers used in this study for real-time PCR assay.

\begin{tabular}{lll}
\hline $\begin{array}{l}\text { Human } \\
\text { Gene } \\
\text { name }\end{array}$ & Forward sequences 5' $\mathbf{~ - > ~ 3 '}$ & Reverse sequences 5' -> 3' \\
\hline GAPDH & ATGACATCAAGAAGGTGGTG & CATACCAGGAAATGAGCTTG \\
NLRP1 & GGACTGACGATGACTTCTGG & ATCACAAAGCAGAGACCCG \\
NLRP3 & GTGTTTCGAATCCCACTGTG & TCTGCTTCTCACGTACTTTCTG \\
NLRC4 & CAGTCCCCTCACCATAGAAG & TCAAGTTACCCAAGCTGTCAG \\
NLRP6 & TCTTCATCCACTCTTTCAGGC & CTCAGAAAGGTCTCGGCAG \\
AIM2 & TGAAACCCCGAAGATCAACAC & CCCAGTACTTCCATTTTCCCAG \\
MMP3 & GACAAAGGATACAACAGGGAC & TGAGTGAGTGATAGAGTGGG \\
MMP9 & CGAACTTTGACAGCGACAAG & CACTGAGGAATGATCTAAGCCC \\
COL1A1 & CCGGCTCCTGCTCCTCTTAGCG & CGTTCTGTACGCAGGTGATTGGTGG \\
ACTA2 & CATCCTCATCCTCCCTTGAG & ATGAAGGATGGCTGGAACAG \\
\hline
\end{tabular}

